\title{
ARTICLE
}

\section{Selective deletion of the soluble Colony-Stimulating Factor 1 isoform in vivo prevents estrogen-deficiency bone loss}

\section{in mice}

\author{
Gang-Qing Yao ${ }^{1}$, Nancy Troiano ${ }^{2}$, Christine A Simpson ${ }^{1}$ and Karl L Insogna ${ }^{1}$
}

\begin{abstract}
Neutralizing CSF1 in vivo completely prevents ovariectomy (OVX)-induced bone loss in mice. There are two isoforms of CSF1, soluble (sCSF1), and membrane-bound (mCSF1), but their individual biological functions are unclear. It had been previously reported that mCSF1 knockout $(\mathrm{K} / \mathrm{O})$ and wild type $(\mathrm{Wt})$ female mice experience the same degree of bone loss following OVX. In Wt mice the expression of sCSF1 was elevated fourfold in skeletal tissue following OVX while expression of MCSF1 was unchanged. To examine the role of sCSF1 in OVX-induced bone loss, mice were engineered in which SCSF1 was not expressed but expression of mCSF1 was unaffected (sCSF1 K/O). Isoform-specific reverse transcription PCR confirmed the absence of transcripts for SCSF1 in bone tissue isolated from these animals and no circulating CSF1 was detected by ELISA. Surprisingly, there were no significant differences in bone mineral density (BMD) between sCSF1 $\mathrm{K} / \mathrm{O}$ mice and Wt controls as assessed by dual-energy X-ray absorptiometry and micro-CT. However, one month after OVX, femoral, spinal and total BMD had declined by $11.2 \%, 8.9 \%$, and $8.7 \%$ respectively in OVX-Wt animals as compared to Sham-OVX. In contrast OVX sCSF1 K/O mice showed changes of $+0.1 \%$, $-2.4 \%$, and $+2.3 \%$ at the same 3 sites compared to Sham-OVX sCSF1 K/O mice. These data indicate important non-redundant functions for the two isoforms of CSF1 and suggest that SCSF1, but not mCSF1, plays a key role in estrogen-deficiency bone loss.
\end{abstract}

Bone Research (2017) 5, 17022; doi:10.1038/boneres.2017.22; published online: 14 November 2017

\section{INTRODUCTION}

Alternative splicing is the major source of proteome diversity. ${ }^{1-2}$ Mutations in splicing sites and changes in the relative expression levels of isoforms have been implicated in the pathogenesis of human diseases..$^{3-4}$

Colony-stimulating factor 1 (CSF1) is one of two cytokines absolutely required for osteoclastogenesis. Multiple human CSF1 mRNA species $(4.0,3.0,2.3,1.9$, and $1.6 \mathrm{~kb})$ are transcribed from the CSFl gene, ${ }^{5-9}$ and molecular cloning of CDNAs derived from these transcripts has demonstrated that the size differences are due to alternative splicing in exon 6 and the alternative use of the $3^{\prime}$-end of exons 9 and $10 .^{6-8}$ The 1.6 and $3.0 \mathrm{~kb}$ CSF1 cDNAs give rise, by alternative splicing, to a short exon 6 in which the site for proteolytic cleavage of the CSF1 precursor has been spliced out. Thus, the products of the 1.6- and $3.0 \mathrm{~kb}$ cDNAs are cell-surface (membrane-bound) glycoproteins, which are slowly and inefficiently released from the cell surface by extracellular proteolysis. ${ }^{9-10}$ By contrast, the products of the $1.9,2.3$, and $4.0 \mathrm{~kb}$ cDNAs have intermediate or long versions of exon 6 in which the proteolytic cleavage site is intact, giving rise to a soluble, rapidly secreted growth factor. ${ }^{11-12}$ Similar findings have been reported for the murine CSFl gene. ${ }^{13-14}$

The role of these two isoforms in pathologic states of bone remodeling has not been extensively studied. Friel et al reported that mCSF1 supported long-term proliferation of hematopoietic precursor cells, as well as selfrenewal of this population. ${ }^{15}$ In contrast, SCSF1 did not support a self-renewing population of progenitors but

'Department of Internal Medicine, Yale University School of Medicine, New Haven, USA and ${ }^{2}$ Department of Orthopaedics, Yale University School of Medicine, New Haven, USA

Correspondence: Gang-Qing Yao (gang-qing.yao@yale.edu)

Received: 28 December 2016; Revised: 7 March 2017; Accepted: 19 March 2017 
rather drove cells to differentiate into monocytes and macrophages. Douglass et al. ${ }^{16}$ reported that mCSF1 promotes prolonged signal transduction in bone-marrowderived macrophages. Perhaps related to this latter observation, macrophages can kill mCSF1-positive tumor cells ${ }^{17-18}$ but not sCSF1-positive cells. ${ }^{19}$ We have shown that human and mouse osteoblasts also express mCSFl, that PTH and TNF increase expression of the MRNA and protein product, and, most importantly from a physiologic standpoint, that mCSF1 supports the formation of osteoclast-like cells in a dose-dependent manner in vitro and at physiologic concentrations acts synergistically with SCSF1 to induce osteoclast formation. ${ }^{20-21}$ Further, we have found that selective expression of mCSFl alone in osteoblasts rescues the osteopetrotic phenotype of op/op mice. ${ }^{22}$ Since osteoblast-derived SCSF1 does not induce osteoclastlike cells (OCLs) formation in the absence of cell-cell contact, even if RANKL is added, ${ }^{23}$ it appears that mCSF1 may be required for normal osteoclastogenesis.

Kimble et al. $^{24}$ reported that estrogen-withdrawal was associated with increased levels of IL-1 and TNF in bone marrow, which induced the formation of a stromal cell population producing high levels of SCSFI. The emergence of this population of stromal cells correlated with increased osteoclastogenesis. The same group subsequently reported that stromal cells from estrogen-deficient animals demonstrated enhanced phosphorylation of the nuclear transcription factor Egr-1, which causes reduced binding of Egr-1 to the transcriptional activator Sp-1 and higher levels of free Sp-1. ${ }^{25}$ Increased levels of free Sp-1 induce enhanced transactivation of the CSFl gene, leading to increased CSF1 production in the estrogen-deficient state. $^{25}$ The relevance of this molecular pathway for estrogen-deficiency bone loss is supported by the observation that Egr-1 knockout animals demonstrate increased basal rates of bone resorption that do not increase further following ovariectomy $(\mathrm{OVX}) .{ }^{26}$ A neutralizing antibody to CSF1 restored rates of bone resorption to normal in these animals and also completely prevented ovariectomyinduced bone loss in Wt animals. ${ }^{26}$ In the aggregate, these data strongly suggest an important role for SCSFI in estrogen-mediated bone loss. In contrast to these findings, using semi-quantitative reverse transcription PCR, Flanagan and co-workers have reported that estrogen-withdrawal selectively upregulates expression of the cell-surface CSF1 isoform in rat bone marrow cultures. ${ }^{27-28}$

We have selectively deleted mCSF1 in mice and reported that, 1 month after surgery, 5-month-old mCSF1 $\mathrm{K} / \mathrm{O}$ and $\mathrm{W} t$ female mice experienced the same degree of bone loss following OVX. OVX induced a significant fourfold increase in the expression of the SCSFl in the bones of Wt mice while expression of mCSFl was unchanged. ${ }^{29}$ These findings indicate that mCSFl does not appear to be required for estrogen-deficiency bone loss, but SCSFl could play a key role in this pathologic process. To explore the role of SCSF1 in estrogen-deficiency bone loss, we have generated isoform-selective SCSFI K/O mice and report our findings in this model.

\section{MATERIALS AND METHODS}

Generation of SCSF1 K/O mice

The normal splicing patterns of the CSF1 gene that result in expression of both the SCF1 and mCSF1 isoforms are shown in Figure 1a. The targeting construct for deletion of SCSF1 (Figure 1b) introduced a stop codon followed by a lox-p site into exon 6 at a position $3^{\prime}$ to the splice site and proteolytic cleavage sites for SCSF1. The stop codon was designed to include all three reading frames. A Neo cassette with flanking frt sites (lox-p-frt-Neo-frt) was introduced in intron 5.

The linearized targeting vector was electroporated into W9.5 ES cells by the Animal Genomics Services at Yale. Drug-resistant clones were screened by PCR using the primer sets (Forward: 5'-GAAGCCCCTCAGTCTTCCT-3' and Reverse: 5'-GCCTGAAGAACGAGATCAGC-3') and confirmed by Southern analysis. One correctly targeted ES clone was selected for blastocyst injection. The resulting chimeras were mated with Flp-e deleter females to generate $\mathrm{SCSF} 7^{\text {flox/flox }}$ mice. In animals bearing two of these floxed alleles both isoforms of CSF1 are generated. Splicing to the SCSF1 splice site will lead to generation of an mRNA that includes the sequences for the proteolytic cleavage sites for SCSF1 followed by a stop codon. The protein product of this mRNA will yield normal mature SCSF1 since it contains the appropriate signals for proteolytic cleavage as well as the surrounding sequences.

$\mathrm{SCSF}^{\text {flox/flox }}$ mice were then bred to transgenic animals expressing cre under the control of the human beta actin gene promoter to generate $\mathrm{SCSF} 1^{\mathrm{flox} /+} \mathrm{Cre}^{+/-}$mice.

Breeding $\mathrm{SCSF}^{\text {flox/+}} \mathrm{Cre}^{+/}$mice with $\mathrm{SCSFl}^{\text {flox/flox }}$ animals generated mice either expressing cre recombinase, ie SCSFI K/O mice, or mice not expressing cre, which served as Wt controls. The Yale Animal Care and Use Committee approved the use of animals in this study.

Measurement of SCSF1, mCSFl transcripts and protein PCR: MCSFI and SCSFI were detected by reverse transcription PCR. The forward primer for both mCSF1 and SCSF1 is: 5'-ACCAACTGGGACGATATGGAGAAGA-3'; and the reverse primers respectively are for mCSF1: $5^{\prime}-G C T T$ GAGGGCAAGAGAAGTACC-3'; and for SCSF1: 5'-ATCCTT CTATACTGGCAG-3'.

ELISA: mCSF1 expression on murine osteoblast plasma membranes from SCSFI K/O and Wt mice was quantified using a CSF1 ELISA kit from R\&D Systems (Minneapolis, MN, 
a

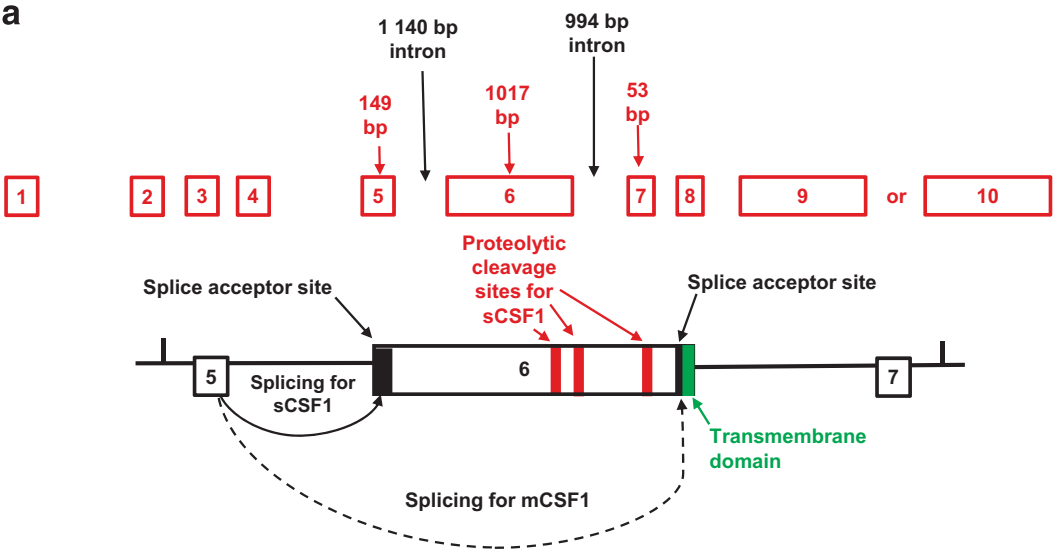

b
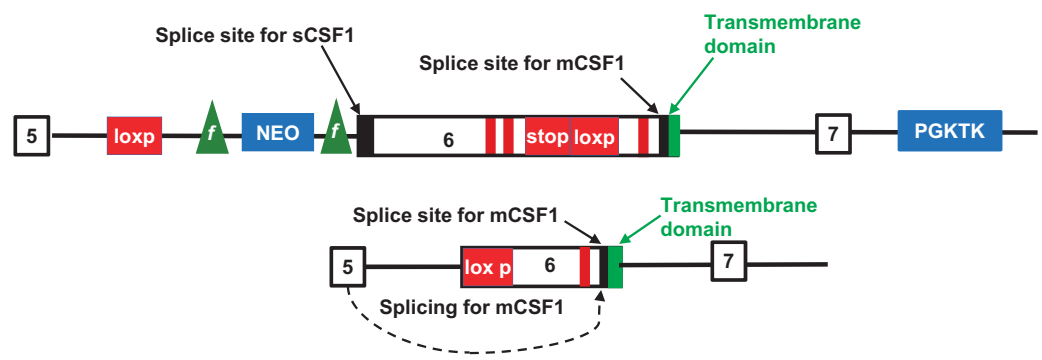

Figure 1. Strategy for generating sCSF1 K/O mice. (a) Splicing pattern for the CSF1 gene. (b) The targeting construct for deletion of sCSF1 introduces a stop codon followed by a lox-p site into exon 6 at a position $3^{\prime}$ to the splicing site for sCSF1. The stop codon is designed to include all three reading frames. The Neo cassette with flanking frt sites (lox-p-frt-Neo-frt) is introduced into intron 5. Excision of the Neo cassette with flp recombinase leads to a CSF1 allele that contains two lox-p sites, one in intron 5, and one which is downstream of the splice site for sCSF1. In animals bearing two of these floxed alleles (that is, before cre-mediated recombination) both isoforms of CSF1 will be generated. Splicing to the sCSF1 splice site will lead to generation of an mRNA that includes the sequences for the proteolyitc cleavage sites for sCSF1, followed by a stop codon. The protein product of this mRNA will yield normal mature sCSF1 since it contains the appropriate signals for proteolytic cleavage with the surrounding sequences. Recombination with cre leads to selective deletion of the splice acceptor site for the sCSF1 isoform. This leaves the splice acceptor site for mCSF1 intact. Thus, a mature functional mCSF1 will be generated, but no sCSF1.

USA) as described previously. ${ }^{22}$ Primary murine osteoblasts were prepared from calvariae of 4 to 7 -day-old mice by serial collagenase-dispase digestion. ${ }^{22}$ Cells were grown in $\alpha$-minimum essential medium, supplemented with $10 \%$ FBS, penicillin, streptomycin, L-glutamine, and $20 \mathrm{mmol} \cdot \mathrm{L}^{-1}$ HEPES. Plasma membranes were extracted as described previously. ${ }^{21}$ Briefly, primary cultured mouse osteoblasts were washed with cold PBS and incubated with lysis buffer $\quad\left(10 \mathrm{mmol} \cdot \mathrm{L}^{-1} \quad\right.$ Tris- $\mathrm{HCl}, \quad \mathrm{pH} \quad 7.4, \quad 10 \mathrm{mmol} \cdot \mathrm{L}^{-1}$ $\mathrm{NaCl}, \quad 1.5 \mathrm{mmol} \cdot \mathrm{L}^{-1} \quad \mathrm{MgCl}_{2} \quad 1 \mathrm{mmol} \cdot \mathrm{L}^{-1}$ dithiothreitol, $0.5 \mathrm{mmol} \cdot \mathrm{L}^{-1}$ phenylmethylsulfonyl fluoride, $0.5 \mu \mathrm{g} \cdot \mathrm{mL}^{-1}$ pepstatin $\mathrm{A}$, and $0.5 \mu \mathrm{g} \cdot \mathrm{mL}^{-1}$ leupeptin) and allowed to swell for $15 \mathrm{~min}$ on ice. The cells were disrupted using a ground glass homogenizer in an ice bath, and the homogenate was centrifuged at $1000 \mathrm{~g}$ for $10 \mathrm{~min}$ to remove nuclear and cellular debris. The supernatant was overlaid on a $35 \%$ sucrose solution and centrifuged for $60 \mathrm{~min}$ at $20000 \mathrm{~g}$. The plasma membranes, which were found in a single band at the interface of the supernatant and sucrose, were collected and centrifuged for $60 \mathrm{~min}$. at $100000 \mathrm{~g}$. The pellets were resuspended and stored at $-70^{\circ} \mathrm{C}$ until assayed. The concentration of plasma membrane protein was determined using a commercially available kit and the manufacturer's recommended protocol (Bio-Rad, Hercules, CA, USA).

To measure circulating levels of CSFl, blood was collected by cardiac puncture from $\mathrm{K} / \mathrm{O}$ mice and $\mathrm{W} t$ littermates, allowed to clot, spun and sera isolated. Circulating levels of CSF1 in these sera were measured using the same murine CSFI ELISA kit described above.

\section{BMD measurements}

In vivo bone mineral density (BMD) measurements were performed by dual-energy X-ray absorptiometry (DXA) using a PIXImus densitometer (Lunar Corporation, Madison, WI, USA). Anesthetized mice (ketamine, $30 \mathrm{mg} \cdot \mathrm{kg}^{-1}$ body-Wt and xylazine, $3 \mathrm{mg} \cdot \mathrm{kg}^{-1}$ body-Wt given intraperitoneally) were placed in the prone position and scans performed with a 1.270-mm-diameter collimator, 0.762-mm line spacing, 0.380-mm point resolution and an acquisition time of $5 \mathrm{~min}$. The spine window is a rectangle spanning a length of the spine from $\mathrm{Tl}$ to the beginning of the sacrum. 
The femur window encompasses the entire right femur of each mouse. The coefficient of variation for total-body $\mathrm{BMD}$ is $\sim 1.5 \%$.

Micro-CT. Femurs were stripped of soft tissue and stored in $70 \% \mathrm{EtOH}$ at $4{ }^{\circ} \mathrm{C}$. Specimens were analyzed in $70 \%$ $\mathrm{E} \mathrm{OH}$ by cone beam microfocus X-ray computed tomography using a Scanco $\mu \mathrm{CT}$-35 instrument (Scanco, Brutissellen, Switzerland). Images were acquired at $55 \mathrm{kV}$ $\mathrm{p}$, with an integration time of $500 \mathrm{~ms}$ and an isometric voxel size of $6 \mathrm{~mm}$. Segmentation of bone from marrow and soft tissue was performed in conjunction with a constrained Gaussian filter (support $=1 ; 3 \times 3 \times 3$ voxel window; $\sigma=0.8$ ) to reduce noise, applying density thresholds of 250 and 420 for the trabecular and cortical compartments of the femur, respectively. Volumetric regions for trabecular analysis were selected within the endosteal borders of the distal femoral metaphysis to include the secondary spongiosa located $1 \mathrm{~mm}$ from the growth plate and extending $1 \mathrm{~mm}$ proximally. Cortical morphometry was quantified and averaged volumetrically through 233 serial cross-sections $(1.4 \mathrm{~mm})$ centered on the diaphyseal midpoint between proximal and distal growth plates.

Bone histomorphometry

Histomorphometry was performed as previously reported. ${ }^{30-32}$ At the time of sacrifice, the tibiae were removed, stripped of soft tissue, and fixed in $70 \%$ ethanol. Tibiae were then dehydrated through graded ethanol, cleared in tolvene, infiltrated with increasing concentrations of methylmethacrylate, and embedded in methylmethacrylate according to previously described methods. ${ }^{30-31}$ Analyses were performed on $5 \mu \mathrm{mol} \cdot \mathrm{L}^{-1}$ thick sections stained with tolvidine blue, $\mathrm{pH} 3.7$ using a Nikon microscope interfaced with the Osteomeasure system software and hardware (Osteometrics, Atlanta, GA, USA). Measurements were obtained in an area of cancellous bone that measured $\sim 2.5 \mathrm{~mm}^{2}$, containing only secondary spongiosa, and located $0.5-2.5 \mathrm{~mm}$ distal to the epiphyseal growth cartilage. Longitudinal sections ( $5 \mu \mathrm{m}$ thick) taken in the frontal plane through the cancellous bone of the proximal tibia were prepared with a Leica RM2165 microtome, mounted on chrom-alum-coated glass slides, and stained with tolvidine blue, $\mathrm{pH}$ 3.7. All indices were defined according to the American Society of Bone and Mineral Research histomorphometry nomenclature. ${ }^{33}$

\section{Ovariectomy}

Ovariectomy (OVX) was accomplished through a paralumbar incision in anesthetized animals as previously reported. ${ }^{34}$ Each ovarian bursa opposite each ovarian hilum was incised, the ovarian hilum exposed and clamped, and the ovary was removed. Sham ovariectomy animals underwent anesthesia and the paralumbar incision without removal of the ovaries. Four weeks after ovariectomy, BMD was determined by DXA.

Statistical analyses

Two-way analysis of variance with, when appropriate, post hoc testing was used to analyze the DXA data. Nonparametric Mann-Whitney test was used to analyze the micro-CT data. Graph Pad Prism v7.0 (La Jolla, CA, USA) was used for these analyses.

\section{RESULTS}

Confirmation of isoform-selective deletion of SCSFl

To determine whether our molecular strategy resulted in isoform-selective deletion of SCSFI, RNA was isolated from tibiae of eight-week-old $\mathrm{W} \dagger$ and SCSFI K/O mice. Isoform-specific quantitative reverse transcription $P C R$ confirmed the absence of SCSFI transcripts in SCSFI K/O mice. However, both Wt and SCSFI K/O mice expressed the transcript for mCSFl (Figure 2). Circulating levels of CSFl from $20 \mathrm{Wt}$ and $20 \mathrm{sCSF} \mathrm{K} / \mathrm{O}$ animals were determined. The mCSFl concentrations in isolated osteoblast membranes prepared from five $\mathrm{W} t$ and five sCSFl K/O mice were also examined and no significant difference was observed between $\mathrm{Wt}$ and sCSFl K/O mice $(P>0.05)$. The results are summarized in Table 1.

\section{sCSFl K/O mice have normal BMD}

Femur, spine, and total-body BMD determined by DXA are shown in Figure 3a: Femur: W† $(0.0806 \pm 0.0018)$ vs K/O $(0.0781 \pm 0.0017) \mathrm{g} \cdot \mathrm{cm}^{-2}$; Spine: W† $(0.0634 \pm 0.0011) \mathrm{vs}$ $\mathrm{K} / \mathrm{O} \quad(0.0622 \pm 0.0008) \mathrm{g} \cdot \mathrm{cm}^{-2}$; Total body: W† $(0.0527 \pm 0.0007)$ vs $\mathrm{K} / \mathrm{O}(0.0527 \pm 0.0007) \mathrm{g} \cdot \mathrm{cm}^{-2}$. There

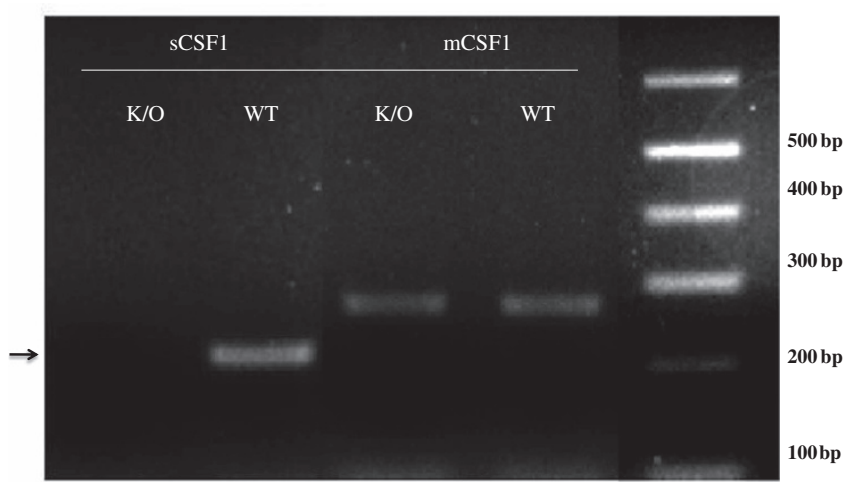

Figure 2. Determination of sCSF1 RNA expression levels in sCSF1 $\mathrm{K} / \mathrm{O}$ mice. Isoform-specific RT-PCR of bone RNA demonstrates the absence of sCSF1 transcripts in sCSF1 K/O mice. Arrow indicates the expected amplicon, which is present in Wt but not in $\mathrm{K} / \mathrm{O}$ animals. $\mathrm{K} / \mathrm{O}$, knockout; RT-PCR, reverse transcription PCR. 
were no significant differences in bone density at any site between SCSFI K/O mice and controls when analyzed by two-way analysis of variance. When analyzed by micro-CT there were again no significant differences noted between

Table 1. Measurements of sCSF1 and mCSF1 protein levels in sCSF1 K/O mice

\begin{tabular}{|c|c|c|c|}
\hline Proteins & $N$ & W† & $\mathrm{K} / \mathrm{O}$ \\
\hline Serum sCSF1/(pg.mL $\left.{ }^{-1}\right)$ & 40 & $1052 \pm 52$ & None detected \\
\hline $\begin{array}{l}\text { Cell-associated } \mathrm{mCSF} 1 \mathrm{pg} \cdot \mathrm{mg}^{-1} \\
\text { membrane protein) }\end{array}$ & 10 & $202 \pm 26$ & $160 \pm 18$ \\
\hline
\end{tabular}

$\mathrm{K} / \mathrm{O}$, knockout; $\mathrm{Wt}$, wild type.
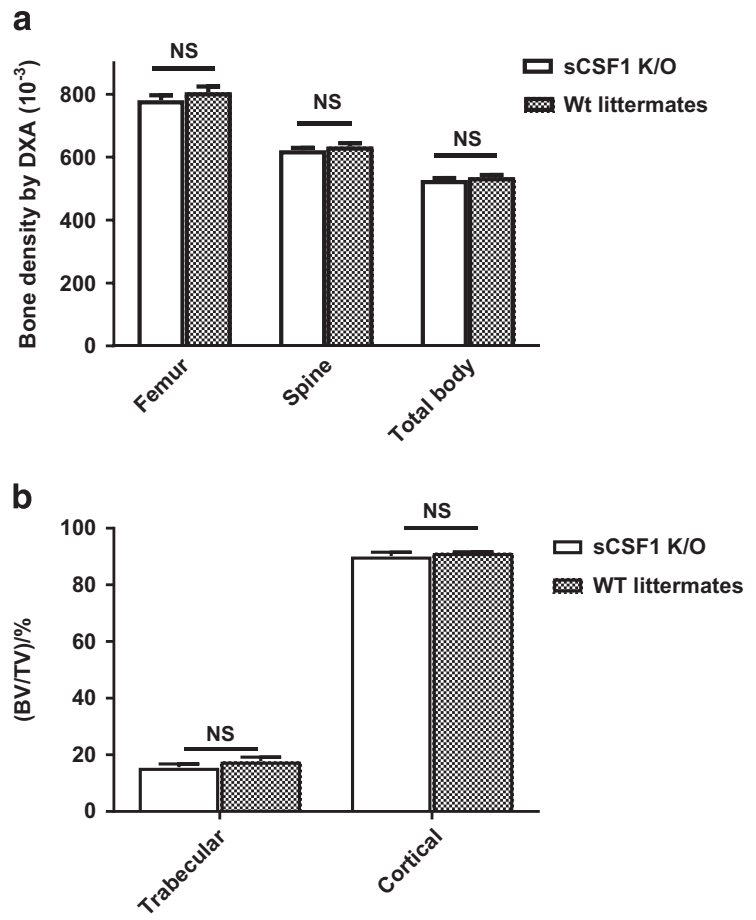

Figure 3. sCSF1 K/O mice have normal bone density. (a) Femur, spine, and total-body BMD determined by DXA in $37 \mathrm{Wt}$ (17 male and 20 female) and 48 K/O (19 male and 29 female) mice. (b) Femoral trabecular and cortical bone mass assessed by micro-CT in sCSF1 K/O animals (10 male and 10 female animals of each genotype). Results are expressed as $\mathrm{M} \pm$ s.e.m. and analyzed by two-way ANOVA for the data in $\mathbf{a}$ and by Mann-Whitney for the data in $\mathbf{b}$. ANOVA, analysis of variance; $\mathrm{BMD}$, bone mineral density; DXA, dual-energy X-ray absorptiometry; K/O, knockout; $\mathrm{M}$, mean; NS, not significant; Wt, wild type.

Table 2. Histomorphometry in sCSF1 K/O and Wt-OVX mice

\begin{tabular}{|c|c|c|c|c|c|c|c|c|}
\hline Mice types & $N$ & $\begin{array}{c}\text { (Obs/BS)/ } \\
\%\end{array}$ & $(\mathrm{Obs} / \mathrm{Os}) / \%$ & $\begin{array}{c}(\mathrm{NOb} / \mathrm{TAR}) / \\
\mathrm{mm}^{-2}\end{array}$ & $\begin{array}{c}(\mathrm{Nob} / \mathrm{BPm}) / \\
\mathrm{mm}^{-2}\end{array}$ & $\begin{array}{c}\text { (Ocs/BS)/ } \\
\%\end{array}$ & $\begin{array}{c}\text { (NOc/TAR)/ } \\
\#\end{array}$ & $\begin{array}{c}(\mathrm{NOc} / \mathrm{BPm}) / \\
\mathrm{mm}^{-2}\end{array}$ \\
\hline sCSFI K/O OVX & 6 & $6.77 \pm 1.05$ & $54.58 \pm 2.28$ & $62.66 \pm 11.38$ & $6.54 \pm 1.06$ & $4.30 \pm 0.93$ & $10.84 \pm 1.57$ & $1.28 \pm 0.26$ \\
\hline Control OVX & 6 & $8.32 \pm 1.22$ & $51.54 \pm 1.26$ & $59.22 \pm 8.59$ & $7.97 \pm 1.11$ & $15.22 \pm 2.4$ & $34.82 \pm 5.04$ & $4.62 \pm 0.61$ \\
\hline
\end{tabular}

SCSF1 K/O and control mice: Data are shown in Figure 3b: Trabecular BV/TV: Wt $(17.8 \pm 0.1) \%$ vs K/O $(15.6 \pm 0.01) \%$; Cortical BV/TV: W† $(91.5 \pm 0.02) \%$ vs K/O $(90.2 \pm 0.1) \%$.

The genetic absence of SCSF1 attenuates estrogendeficiency bone loss

To examine the impact of the genetic absence of SCSF1 on estrogen-deficiency bone loss, 19-22-week-old SCSF1 $\mathrm{K} / \mathrm{O}$ and control female mice undenwent OVX or shamOVX. The results from two independent experiments are summarized in Figure 4 representing data from a total of 69 mice. Mean BMD values in Wt mice were: femur: OVX $(0.0826 \pm 0.0034)$ vs sham-OVX $(0.0929 \pm 0.0020) \mathrm{g} \cdot \mathrm{cm}^{-2}$; spine: OVX $(0.0686 \pm 0.0026)$ vs sham-OVX $(0.0753 \pm$ $0.0018) \mathrm{g} \cdot \mathrm{cm}^{-2}$; total body: OVX $(0.0590 \pm 0.0006)$ vs shamOVX $(0.0650 \pm 0.0006) \mathrm{g} \cdot \mathrm{cm}^{-2}$. In $\mathrm{K} / \mathrm{O}$ mice mean BMD were: femur: OVX $(0.0730 \pm 0.0041)$ vs sham-OVX $(0.0730 \pm$ $0.0040) \mathrm{g} \cdot \mathrm{cm}^{-2}$; spine: OVX $(0.0631 \pm 0.0033)$ vs sham-OVX $(0.0647 \pm 0.0021) \mathrm{g} \cdot \mathrm{cm}^{-2}$; total body: OVX $(0.0562 \pm 0.0012)$ vs sham-OVX $(0.0549 \pm 0.0012) \mathrm{g} \cdot \mathrm{cm}^{-2}$. Spinal bone density declined by $8.9 \%$ in control animals, while it only declined by $2.3 \%$ in the sCSF1 K/O mice. At the femur, BMD declined by $11.2 \%$ in controls but there was little change in BMD at this skeletal site in the SCSF1 K/O mice. Total BMD fell by $8.7 \%$ in the control animals, but increased by $2.3 \%$ in the $\mathrm{K} / \mathrm{O}$ animals (Figure 4a). The differences in the degree of bone loss at the spine, femur, and total-body BMD were statistically significant based on genotype by two-way analysis of variance. The results of micro-CT analyses of femoral BMD were consistent with the above DXA findings. In particular, trabecular BV/TV in the OVX-Wt mice declined by $29 \%$ but increased $25 \%$ in OVX-K/O mice and the difference in mean BMD after OVX was statistically significantly different based on genotype (Figure $4 \mathrm{~b}$ and $\mathrm{c}$ ).

OVX does not increase osteoclast number in SCSF1 K/O mice

To explore the cellar basis for the differential response to OVX in Wt and SCSFl K/O mice, histomorphometric analyses were performed on femoral trabecular bone in both groups of animals 1 month after OVX (Table 2). The numbers of osteoblasts, whether expressed referent to bone surface, osteoid surface, total area or bone perimeter were similar in SCSFI K/O and control mice. In contrast, OVX-K/O mice had significantly lower numbers of 

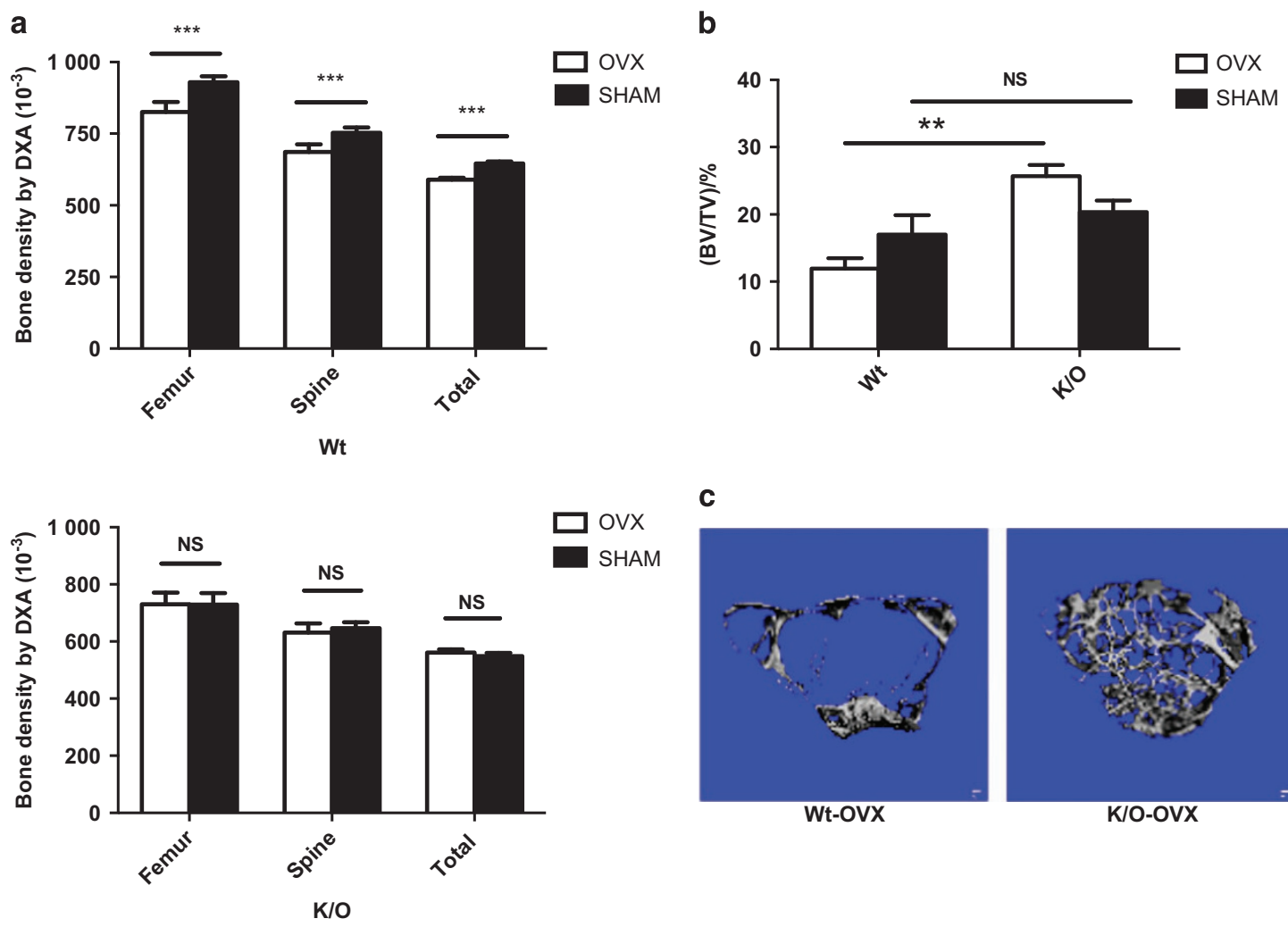

C

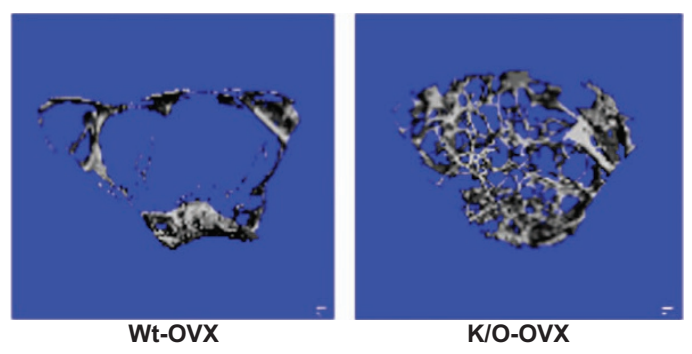

Figure 4. sCSF1 K/O mice are protected against estrogen-deficiency bone loss. (a) Mean BMD values determined by DXA in Wt mice (upper panel) and K/O mice (bottom panel) following sham-OVX or OVX. (b) Femoral trabecular BV/TV assessed by micro-CT. (c) 3D reconstructions of micro$\mathrm{CT}$ images of diaphyseal bone in Wt-OVX and K/O-OVX. Note the greater amount of trabecular bone in the K/O-OVX animals. Results are expressed as $\mathrm{M} \pm$ s.e.m. and analyzed by two-way ANOVA for the data in a and by Mann-Whitney for the data in $\mathbf{b}$. ANOVA, analysis of variance; $\mathrm{BMD}$, bone mineral density; K/O, knockout; $\mathrm{M}$, mean; NS, not significant; OVX, ovariectomy, ${ }^{* * *} P<0.0001,{ }^{* *} P=0.02$.

osteoclasts compared to the number of osteoclasts in OVX-Wt mice whether referent to bone surface, total area or bone perimeter.

\section{DISCUSSION}

Although, CSF1 is required for osteoclastogenesis, the relative importance of the two CSF1 isoforms in mediating osteoclastogenesis, as well as their individual roles in skeletal homeostasis, remain incompletely understood.

As noted in the Introduction, selective deletion of MCSFl in mice resulted in an increase in bone mass but did not affect the degree of bone loss following ovariectomy. In contrast to those studies, the current work demonstrates that SCSF 1 - at least in mice - is dispensable for maintaining normal skeletal mass and normal rates of bone turnover. Thus, there was no difference in bone mass in the SCSFl $\mathrm{K} / \mathrm{O}$ mice as compared to littermate controls, whether assessed by DXA or by micro-CT. The data are surprising in so far as SCSF1 is generally considered the major and most important form of CSF1, since it is the principal contributor to the circulating form of the molecule. However, CSFl can be made by a wide variety of cells, so ascribing unique importance of the SCSF1 isoform to bone, based on its circulating concentrations, may be an over-simplification.

While our findings suggest that SCSF1 is not required for normal skeletal acquisition, this isoform may play a role in inflammatory arthritides. Dalbeth et al. ${ }^{35}$ have reported that serum levels of CSF1 are markedly higher in patients with psoriatic arthritis than in patients with psoriasis who do not have joint inflammation. CSFl and its receptor $\mathrm{c}$-fms are more elevated in in the synovium and synovial fluid of patients with rheumatoid arthritis, compared to those with osteoarthritis. ${ }^{36-37}$ An anti-CSFl antibody, an antibody to c-fms, and the c-fms inhibitors Ki20227 and GW2580, have all been shown to significantly reduce the severity of joint disease in a murine model of inflammatory arthritis. ${ }^{36-40}$

In earlier work, we reported the results of selectively overexpressing either sCSFl, mCSFl or both isoforms in osteoblasts in vivo using transgenic technology. We reported that targeted overexpression of human SCSFI, human mCSFl or both $(\mathrm{s} / \mathrm{mCSF} 1)$ in osteoblasts in vivo results in significant osteopenia in all three genotypes. ${ }^{41}$ When analyzed by sex, sCSFl transgenic and m/sCSFl 
double-transgenic female animals, but not mCSF1 transgenic female mice, were found to have lower bone mass than their male littermates. ${ }^{41}$ By breeding CSF1 isoformselective transgenic mice to an op/op background, mice were generated in which a single CSFI isoform was the only source of the cytokine (sCSFlop/op and mSCFlop/ $\mathrm{Op})$. Interestingly, when compared to sham-OVX mice of the same genotype, OVX in sCSFlop/op mice led to a greater loss of spinal BMD $(22.1 \%)$ than was seen in either mCSFlop/op mice (12.9\%) or in $\mathrm{Wt}$ animals. We also demonstrated that there is a selective increase in the expression of SCSFl, but not $\mathrm{mCSFl}$, in Wt osteoblasts cultured in estrogen-deficient media. This is consistent with earlier work by Kimball et al., described in the Introduction, indicating that expression of SCSF 1 was increased in stromal cells isolated from OVX mice.

This, then leads to the central hypothesis tested in this study, which is that the selective deletion of SCSF1 should attenuate estrogen-deficiency bone loss. Indeed, that is precisely what was observed. Although bone loss was not completely abrogated in the spine it was markedly attenuated at that site, and there was essentially no bone loss in the femur or total body. Thus, the spinal bone density declined by $8.9 \%$ in the control animals as compared to $2.4 \%$ in the SCSF1 $\mathrm{K} / \mathrm{O}$ mice, and bone loss was negligible at femur while the control animals lost $>11.2 \%$ of their bone mass at that site. Interestingly, total-body BMD actually increased in the K/O animals while declining significantly in the controls.

Currently available therapies for estrogen-deficiency bone loss include bisphosphonates, raloxifene and PTHRIagonists. While these agents are effective at attenuating estrogen-deficiency bone loss, all of them have side effects, and so there remains a need for new therapies to maintain bone health in older women. As noted, preclinical data suggest that CSFI may be a viable therapeutic target, since neutralizing CSFl in vivo prevented OVX-induced bone loss. ${ }^{26}$ The availability of neutralizing antibodies to CSFI, which are currently in clinical trials for cancer and bone metastases, ${ }^{42}$ when coupled with the data presented here, suggest that CSFI may be a reasonable target for drug discovery in treating menopausal bone loss.

In summary, the current findings, along with our earlier published work, ${ }^{29,41}$ indicate important non-redundant functions for the two isoforms of CSF1. Expression of MCSF1 is essential for normal skeletal metabolism since, in its absence, bone mass is significantly increased. SCSFl is not required for normal skeletal acquisition, but in its absence the effect of estrogen withdrawal on the skeleton is markedly attenuated. Coupled with the findings alluded to earlier regarding a possible role for SCSF1 in inflammatory arthritides, our findings suggest that SCSF1 may participate in several states of disordered skeletal homeostasis.

\section{Acknowledgements}

This work was supported by a grant from NIH (NIDDK DK045228) to KLI and by the Yale Bone Center.

\section{Competing interests}

The authors declare no conflict of interest.

\section{References}

1 Pan Q, Shai O, Lee LJ et al. Deep surveying of alternative splicing complexity in the human transcriptome by high-throughput sequencing. Nat Genet 2008; 40: 1413-1415.

2 Wang ET, Sandberg R, Luo $S$ et al. Alternative isoform regulation in human tissue transcriptomes. Nature 2008; 456: 470-476.

3 Cooper TA, Wan L, Dreyfuss G. RNA and disease. Cell 2009; 136: 777-793.

4 Ward AJ, Cooper TA. The pathobiology of splicing. J Pathol 2010; 220: 152-163.

5 Cerretti DP, Wignall J, Anderson D et al. Human macrophage-colony stimulating factor: alternative RNA and protein processing from a single gene. Mol Immunol 1988; 25: 761-770.

6 Kawasaki ES, Ladner MB, Wang AM et al. Molecular cloning of a complementary DNA encoding human macrophage- specific colonystimulating factor (CSF-1). Science 1985; 230: 291-296.

7 Ladner MB, Martin GA, Noble JA et al. Human CSF-1: gene structure and alternative splicing of mRNA precursors. EMBO J 1987; 6: 2693-2698.

8 Wong GG, Temple PA, Leary AC et al. Human CSF-1: molecular cloning and expression of 4-kb cDNA encoding the human urinary protein. Science 1987; 235: 1504-1508.

9 Pampfer S, Tabibzadeh S, Chuan FC et al. Expression of colonystimulating factor-1 (CSF-1) messenger RNA in human endometrial glands during the menstrual cycle: molecular cloning of a novel transcript that predicts a cell surface form of CSF-1. Mol Endocrinol 1991; 5: 1931-1938.

10 Rettenmier CW, Roussel MF, Ashmun RA et al. Synthesis of membranebound colony-stimulating factor 1 (CSF-1) and downmodulation of CSF-1 receptors in NIH 3T3 cells transformed by cotransfection of the human CSF-1 and c-fms (CSF-1 receptor) genes. Mol Cell Biol 1987; 7: 2378-2387.

11 Rettenmier CW. Biosynthesis of macrophage colony-stimulating factor (CSF-1): differential processing of CSF-1 precursors suggests alternative mechanisms for stimulating CSF-1 receptors. Curr Top Microbiol Immunol 1989; 149: 129-141.

12 Rettenmier CW, Roussel MF. Differential processing of colonystimulating factor 1 precursors encoded by two human cDNAs. Mol Cell Biol 1988; 8: 5026-5034.

13 Ladner MB, Martin GA, Noble JA et al. cDNA cloning and expression of murine macrophage colony-stimulating factor from L929 cells. Proc Natl Acad Sci U S A 1988; 85: 6706-6710.

14 Kawasaki ES, Ladner MB. Molecular biology of macrophage colony-stimulating factor. Immunol Ser 1990; 49: 155-176.

15 Friel J, Heberlein C, Itoh $\mathrm{K}$ et al. Role of the stem cell factor (SCF) receptor and the alternative forms of its ligand (SCF) in the induction of long-term growth by stroma cells. Leukemia 1997; 11 (Suppl 3): 493-495.

16 Douglass TG, Driggers L, Zhang JG et al. Macrophage colony stimulating factor: not just for macrophages anymore! A gateway into complex biologies. Int Immunopharmacol 2008; 8: 1354-1376. 
17 Dan Q, Sanchez R, Delgado C et al. Non-immunogenic murine hepatocellular carcinoma Hepa1-6 cells expressing the membrane form of macrophage colony stimulating factor are rejected in vivo and lead to CD8+ T-cell immunity against the parental tumor. Mol Ther 2001; 4: 427-437.

18 Jadus MR, Irwin MC, Irwin MR et al. Macrophages can recognize and kill tumor cells bearing the membrane isoform of macrophage colonystimulating factor. Blood 1996; 87: 5232-5241.

19 Graf MR, Jadus MR, Hiserodt JC et al. Development of systemic immunity to glioblastoma multiforme using tumor cells genetically engineered to express the membrane-associated isoform of macrophage colony-stimulating factor. J Immunol 1999; 163: 5544-5551.

20 Yao GQ, Sun BH, Insogna KL et al. Nuclear factor-kappaB p50 is required for tumor necrosis factor-alpha- induced colony-stimulating factor-1 gene expression in osteoblasts. Endocrinology 2000; 141: 2914-2922.

21 Yao GQ, Sun B, Hammond EE et al. The cell-surface form of colonystimulating factor-1 is regulated by osteotropic agents and supports formation of multinucleated osteoclast- like cells. J Biol Chem 1998; 273: 4119-4128.

22 Yao GQ, Wu JJ, Sun BH et al. The cell surface form of colony-stimulating factor-1 is biologically active in bone in vivo. Endocrinology 2003; 144: $3677-3682$.

23 Itoh K, Udagawa N, Matsuzaki K et al. Importance of membrane- or matrix-associated forms of M-CSF and RANKL/ODF in osteoclastogenesis supported by $\mathrm{SaOS}-4 / 3$ cells expressing recombinant PTH/PTHrP receptors. J Bone Miner Res 2000; 15: 1766-1775.

24 Kimble RB, Srivastava S, Ross FP et al. Estrogen deficiency increases the ability of stromal cells to support murine osteoclastogenesis via an interleukin-1and tumor necrosis factor- mediated stimulation of macrophage colony-stimulating factor production. J Biol Chem 1996; 271: 28890-28897.

25 Srivastava S, Weitzmann MN, Kimble RB et al. Estrogen blocks M-CSF gene expression and osteoclast formation by regulating phosphorylation of Egr-1 and its interaction with Sp-1. J Clin Invest 1998; 102: 1850-1859.

26 Cenci S, Weitzmann MN, Gentile MA et al. M-CSF neutralization and egr-1 deficiency prevent ovariectomy-induced bone loss. J Clin Invest 2000; 105: 1279-1287.

27 Lea CK, Sarma U, Flanagan AM. Macrophage colony stimulating-factor transcripts are differentially regulated in rat bone-marrow by gender hormones. Endocrinology 1999; 140: 273-279.

28 Sarma U, Edwards M, Motoyoshi K et al. Inhibition of bone resorption by 17beta-estradiol in human bone marrow cultures. J Cell Physiol 1998; 175: 99-108.

29 Yao GQ, Wu JJ, Troiano N et al. Selective deletion of the membranebound colony stimulating factor 1 isoform leads to high bone mass but does not protect against estrogen-deficiency bone loss. J Bone Miner Metab 2012; 30: 408-418.

30 Insogna KL, Stewart AF, Vignery AM et al. Biochemical and histomorphometric characterization of a rat model for humoral hypercalcemia of malignancy. Endocrinology 1984; 114: 888-896.
31 Recker R (ed.). Techniques and Interpretation// Baron R, Vignery A, Neff L et al. Bone histomorphometry. Boca Raton: CRC Press, 1983: 31-32.

32 Knopp E, Troiano N, Bouxsein M et al. The effect of aging on the skeletal response to intermittent treatment with parathyroid hormone. Endocrinology 2005; 146: 1983-1990.

33 Parfitt AM, Drezner MK, Glorieux FH et al. Bone histomorphometry: standardization of nomenclature, symbols, and units. Report of the ASBMR Histomorphometry Nomenclature Committee. J Bone Miner Res 1987; 2: 595-610.

34 Ovadia S, Insogna K, Yao GQ. The cell-surface isoform of colony stimulating factor 1 (CSF1) restores but does not completely normalize fecundity in CSF1-deficient mice. Biol Reprod 2006; 74: 331-336.

35 Dalbeth N, Pool B, Smith T et al. Circulating mediators of bone remodeling in psoriatic arthritis: implications for disordered osteoclastogenesis and bone erosion. Arthritis Res Ther 2010; 12: R164.

36 Paniagua RT, Chang A, Mariano MM et al. c-Fms-mediated differentiation and priming of monocyte lineage cells play a central role in autoimmune arthritis. Arthritis Res Ther 2010; 12: R32.

37 Toh ML, Bonnefoy JY, Accart N et al. Bone- and cartilage-protective effects of a monoclonal antibody against colony-stimulating factor 1 receptor in experimental arthritis. Arthritis Rheumatol 2014; 66: 2989-3000.

38 Garcia S, Hartkamp LM, Malvar-Fernandez B et al. Colony-stimulating factor (CSF) 1 receptor blockade reduces inflammation in human and murine models of rheumatoid arthritis. Arthritis Res Ther 2016; 18: 75.

39 Ohno H, Uemura Y, Murooka H et al. The orally-active and selective c-Fms tyrosine kinase inhibitor Ki20227 inhibits disease progression in a collagen-induced arthritis mouse model. Eur J Immunol 2008; 38: 283-291.

40 Campbell IK, Rich MJ, Bischof RJ et al. The colony-stimulating factors and collagen-induced arthritis: exacerbation of disease by M-CSF and G-CSF and requirement for endogenous M-CSF. J Leukoc Biol 2000; 68: 144-150.

41 Yao GQ, Wu JJ, Ovadia S et al. Targeted overexpression of the two colony-stimulating factor-1 isoforms in osteoblasts differentially affects bone loss in ovariectomized mice. Am J Physiol Endocrinol Metab 2009; 296: E714-E720.

42 Medina-Echeverz J, Aranda F, Berraondo P. Myeloid-derived cells are key targets of tumor immunotherapy. Oncoimmunology 2014; 3: e28398.

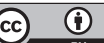

This work is licensed under a Creative Commons Attribution 4.0 International License. The images or other third party material in this article are included in the article's Creative Commons license, unless indicated otherwise in the credit line; if the material is not included under the Creative Commons license, users will need to obtain permission from the license holder to reproduce the material. To view a copy of this license, visit http:/ / creativecommons.org/licenses/by/4.0/

(C) The Author(s) 2017 